\title{
Alain de Weck (1928-2013)
}

\author{
Fribourg, Switzerland
}

Year of birth

1928

Place(s) of university education

Medical studies, 1947-1953, at the universities of Fribourg (Switzerland), Lausanne (Switzerland), Paris (France) and Geneva (Switzerland)

Swiss Federal Physician Diploma, Geneva, 1953

Who were your most important teachers in allergology?

Werner Jadassohn (dermatology/allergy, Geneva), Herman Eisen (immunochemistry/immunology, St. Louis)

Please list your 5 most important publications

de Weck AL, Eisen HN: Some immunochemical properties of penicillenic acid: an antigenic determinant derived from penicillin. J Exp Med 1960;112: 1227-1247.

de Weck AL, Girard JP: Specific inhibition of allergic reactions to penicillin in man by a monovalent hapten. II. Clinical studies. Int Arch Allergy Appl Immunol 1972;42:798-815.

Frey JR, de Weck AL, Geleick H, Polak L: The induction of immunological tolerance during the primary response. Int Arch Allergy Appl Immunol 1972;42:278-299.
Geczy CL, Geczy AF, de Weck AL: Antibodies to guinea pig lymphokines. II. Suppression of delayed hypersensitivity reactions by a 'second generation' goat antibody against guinea pig lymphokines. J Immunol 1976;117:66-72.

Geczy AF, de Weck AL, Geczy CL, Toffler O: Suppression of reaginic antibody formation in guinea pigs by anti-idiotypic antibodies. J Allergy Clin Immunol 1978;62:261-270.

Nakagawa T, Stadler BM, de Weck AL: Flow-cytometric analysis of human basophil degranulation. I. Quantification of human basophils and their degranulation by flow-cytometry. Allergy 1981;36:3947.

Blaser K, de Weck AL: Regulation of the IgE antibody response by idiotype-anti-idiotype network. Prog Allergy 1982;32:203-264.

de Weck AL, Kristensen F, Joncourt F, Bettens F, Walker C, Wang Y: Lymphocyte proliferation, lymphokine production, and lymphocyte receptors in ageing and various clinical conditions. Springer Semin Immunopathol 1984;7:273-289.

Kurimoto Y, de Weck AL, Dahinden CA: Interleukin 3-dependent mediator release in basophils triggered by C5a. J Exp Med 1989;170:467-479.

Alain de Weck sadly deceased in the course of the preparation of this book in 2013. 
Bischoff SC, Baggiolini M, de Weck AL, Dahinden CA: Interleukin 8-inhibitor and inducer of histamine and leukotriene release in human basophils. Biochem Biophys Res Commun 1991;179: 628-633.

de Weck AL: The Carl Prausnitz Memorial Lecture: what can we learn from the allergic zoo? Int Arch Allergy Immunol 1995;107:13-18.

Sanz ML, Maselli JP, Gamboa PM, Oehling A, Diéguez I, de Weck AL: Flow cytometric basophil activation test: a review. J Investig Allergol Clin Immunol 2002;12:143-154.

de Weck AL, Sanz ML: Cellular allergen stimulation test (CAST) 2003, a review. J Investig Allergol Clin Immunol 2004;14:253-273.

Sanz ML, Gamboa PM, de Weck AL: Cellular tests in the diagnosis of drug hypersensitivity. Curr Pharm Des 2008;14:2803-2808.

Have you ever had a function as a President and/ or Secretary General of an allergological society?

Swiss Society of Allergy and Immunology: President

International Association of Allergology and Clinical Immunology (IAACI): Treasurer, VicePresident, President (1985-1988)

International Union of Immunological Societies (IUIS): Secretary General (Founder 1970-1982), President (1983-1986)

Collegium Internationale Allergologicum: Secretary General, President

Honorary Fellow of several allergological and immunological societies (American Academy of Allergy, American College of Allergy, American Academy of Physicians, Deutsche Gesellschaft für Allergologie, Gesellschaft of Immunologie, Société Française d'Immunologie, Österreichische Gesellschaft für Allergologie und Immunologie, etc.)

\section{Which position has had the greatest impact on} your professional life?

Doubtlessly, thanks to my double appointments in the main international societies for allergology and immunology over almost 2 decades, I had unique opportunities to influence both fields and to create bridges between the two disciplines with the help of many scientists. My main objectives during that time (1970-1995), particularly within the IAACI, were to foster basic research in allergology and its applications to clinical practice, e.g. through standardization of allergens and allergy diagnostic practices.

Under my successors, particularly under the impulse of Gunnar Johansson, the priorities of the IAACI have switched somewhat to education of allergologists and allergic patients, professional endeavors and co-operation with the pharmaceutical industry in allergy, tasks which are all also important for the development of allergy in a changing world.

\section{Questions about your professional life}

What brought you to allergy?

What brought me to allergy was in fact a hazard. Around 1952, after obtaining my diploma as a physician at the University of Geneva, I started an internship in dermatology but had to present a thesis in order to obtain an MD degree. Werner Jadassohn, the chairman of dermatology and quite famous at the time, suggested that I should repeat the seminal experiment of Merrill Chase, who had been the first to transfer specific contact dermatitis to haptens in guinea pigs with lymphoid cells and proved thereby that delayed-type hypersensitivity is caused by sensitized lymphocytes. However, he had not confirmed by histology that the skin sensitivity transferred was really contact dermatitis.

For the first 6 months, I used many guinea pigs in my free time, but was unable to reproduce Chase's experiment. This hurt my self-pride and pushed me to persist. After some technical improvements, I finally succeeded and could confirm histologically the experimental transfer of contact dermatitis, which formed the topic of one of my first publications.

After completion of the internship and clinical training in dermatology/allergy, I continued with experimental allergy and immunology at the Department of Pathology in Geneva and then, in 1958, started a postdoc fellowship at the Division of Dermatology, Washington University, St. Louis, USA, under Herman Eisen. 
From whom (academic, teacher) did you learn the most?

After my basic teachers Werner Jadassohn (dermatology) and Erwin Rutishauser (pathology), who taught me the basic tools of academic research (sense of observation, intellectual curiosity, requirements for exactitude, clarity of writing), the man who had the most profound influence on my scientific development was doubtlessly Herman Eisen. Gifted with a brilliant imagination, an exacting and patient request for the truth as well as a humility contrasting with the rush to publication all too frequent at the time, Herman really implanted in me the passion for basic and applied research, a bridge function which has sustained the rest of my academic life.

Later on, as I was on my own in the small Allergy Division I created in Bern upon my return from the USA, were probably Jack Pepys, chief of allergy at the Brompton Hospital, and Michael Sela, chief of immunochemistry at the Weizman Institute.

What was your greatest achievement in allergy?

Due to my work within several institutions (Institute of Clinical Immunology, Bern, Switzerland; Department of Allergology, University of Navarra, Spain; Sandoz/Novartis Research Institute, Vienna, Austria; Roche Research, Basel, Switzerland, and research departments of several pharmaceutical companies) over many years, I have addressed several topics and cannot choose one arbitrarily as the greatest achievement. This also reflects a deliberate choice: I have always considered that meaningful or door-opening contributions to several aspects of the discipline and the building-up of a 'school' of future young leaders is a more important achievement for a scientist than the lifelong exploitation of a single discovery or theme.

Accordingly, I, together with my groups, consider that we have made contributions to:

(1) The immunochemical and immunobiochemical mechanisms of penicillin and other drug allergies. After identifying the penicilloyl antigenic determinant mainly responsible for penicillin allergy, it became possible to investigate systematically the molecular mechanism triggering the anaphylactic reaction in man and to confirm the so-called bridging theory, namely the required linkage of specific antibodies at the surface of the effector cells of allergic inflammation. This also paved the way to the first application of univalent hapten inhibition of clinical allergic reactions in man.

(2) The early recognition of lymphokines as basic intercellular messengers in immediate and delayed reactions. Since the early 1970s, we could study the role of cell-produced molecules in the development and regulation of IgE-mediated and delayed-type reactions, in particular through the first reported specific antibodies against some lymphokines and the use of flow cytometry to investigate the role of some lymphokines (IL-2) on the cell cycle and various clinical conditions, and also the identification of several lymphokines such as IL-3, IL-5 and IL-8 on basophil functions. This early phase culminated in the organization of the 2nd International Lymphokine Workshop in 1979 in Switzerland, where the word interleukin' was coined for the first time. This really opened a very vast field for the next 30 years of immunology.

(3) Comparative human and veterinary allergy. Through the study of atopy and IgE-mediated reactions in various species, such as rodents, dogs, cats, horses and monkeys, we have been able to make progress in the understanding of atopy development, genetics and immunobiological mechanisms of allergic diseases.

(4) Development of diagnostic cellular tests in allergy. Studies on allergic lymphocyte reactions in vitro have enabled a better understanding and diagnosis of drug allergies. Similarly, development of tests for leukotrienes and flow cytometric evaluation of basophil activation have provided new diagnostic tools in several allergic conditions.

\section{What was your greatest disappointment?}

The greatest disappointment in my professional life is the reverse side of the medal described above: to have started too many things and opened many other interesting doors which I have not been able to exploit and finish. Also, particularly in the field of cellular diagnostic tests in allergy, to have failed to convince the allergologist community, particularly in the USA, of their interest in clinical routine practice. I have seen too often a new but demanding technology being simply rejected by the majority of people not even prepared to try it. 
What was your most funny experience?

If you are a scientist working in an interesting field, you are bound to have some competitor(s). In the early 1960s, my main competitor in the field of penicillin allergy was Bernard B. Levine from New York, who has made many very valuable contributions to that topic. One day, I saw his latest paper which described a new technique for the detection of anti-penicillin antibodies, apparently much more efficient than mine. My first reaction was of course to try that technique right away. I called my chief technician and gave her the recipe. A few hours later, she came back, all pale and shaky, and told me: 'Professor, it has exploded!!!'

This made me realize that, obviously, here was the perfect scientific crime. If you describe and publish a technique with deadly consequences, you can be sure that your competitors will try it and be smoothly eliminated.

Who would you list among the top 10 allergists of the world? (Please only mention individuals already deceased.)

I will abstain from nominating past historical figures but rather mention more recent pioneers whom I have personally known and appreciated since 1950. Among these, due to my own orientation, figure less clinical allergists than scientists active in allergy research and immunology related to allergy: Merrill Chase, Zoltan Ovary, Jack Pepys, Bernard Halpern, Jacques Charpin, Otto Westphal, Roy Patterson, Mario Ricci.
Who would you list among the top 10 living

allergists?

My priority goes to those who have contributed to the field by continuous and varied contributions and who have built a 'school' of young leaders rather than to those who have become known by a single discovery: Frank Austen, Allen Kaplan, Barry Kay, Jean Bousquet, Johannes Ring, Terumasa Miyamoto, Dietrich Kraft, Gianni Marone, Alberto Oehling, Mike Kaliner.

What do you see as the greatest problem for allergy in the next 10 years?

The greatest challenge of allergy is to understand the genetic and environmental basis for the development of the atopic march and to achieve its prevention and/or reversal, even after it has started. There are still several approaches which may be followed: epigenetic interventions, induction of primary or secondary tolerance, IgE regulation.

What will be the next great breakthrough in allergy in the next 10 years?

As indicated above, the greatest breakthrough would be the clinical possibility to prevent or reverse the development of atopy through targeted immunological intervention(s). We have followed that dream for more than 30 years, but the increasing knowledge of the allergic patient's immune system may make it possible within the next $10-20$ years.

\section{Reference}

De Weck A: Memories: Failures and Dreams. Berlin, Pro Business, 2008, vol 1: One life, many dreams. 